\title{
Evaluation of Rapid Onset of Action of ICS/LABA Combination Therapies on Respiratory Function in Asthma Patients: A Single-Center, Open-Label, Randomized, Crossover Trial
}

\author{
Hiroyuki Ohbayashi (D) - Sahori Kudo · Mitsue Ariga
}

Received: July 27, 2018 / Published online: September 7, 2018

(C) The Author(s) 2018

\section{ABSTRACT}

Introduction: Products based on inhaled corticosteroid (ICS)/long-acting $\beta 2$ agonist (LABA) combinations may provide different clinical benefits. This study was conducted to compare the rapid effects of three such combination products: formoterol/fluticasone (FFC) aerosol (pMDI), formoterol/budesonide (FBC) dry powder inhaler (DPI), and vilanterol/fluticasone furoate (VFC) DPI.

Methods: The study design was a three-armed, randomized, crossover study. Patients included in the study had stable moderate asthma,

Enhanced Digital Content To view enhanced digital content for this article go to https://doi.org/10.6084/ m9.figshare.7000538.

Electronic supplementary material The online version of this article (https://doi.org/10.1007/s41030018-0062-x) contains supplementary material, which is available to authorized users.

H. Ohbayashi $(\varangle) \cdot$ S. Kudo $\cdot$ M. Ariga

Department of Allergy and Respiratory Medicine,

Tohno-Chuo Clinic, 1-14-1, Matsugase-Cho,

Mizunami, Gifu 509-6134, Japan

e-mail: aims_reserve@yahoo.co.jp

H. Ohbayashi · S. Kudo

General Incorporated Association, Academy of

Inhalation Treatment Methods, 1-14-1,

Matsugase-Cho, Mizunami, Gifu 509-6134, Japan defined as an Asthma Control Questionnaire (ACQ) score $\leq 0.75$, and were undergoing step 2 or 3 asthma treatment as defined by JGL2015. Subjects were treated with fluticasone propionate inhaled via Diskus ${ }^{\circledR}$ during a 2-week washout period before randomization. At visit 2 , subjects were randomly assigned in a 1:1:1 ratio to $\mathrm{FFC}, \mathrm{FBC}$, or $\mathrm{VFC}$, and evaluated for changes in pulmonary function over time. At visits 3 and 4, the treatment was switched to another ICS/LABA combination in a crossover manner after a 1-week washout period. Spirometry was performed pre-dose and at 3, 10, and $30 \mathrm{~min}$ post-dose, and forced oscillation was implemented pre-dose and at $1,7,15$, and 60 min post-dose.

Results: Fifteen outpatients $(63.3 \pm 9.5$ years, ACQ: $0.13 \pm 0.19)$ completed the study. $\Delta \mathrm{FEV}_{1}$ at 3 min did not significantly differ among the three groups. Significant increases in $\mathrm{FEV}_{1}$ and $\% \mathrm{FEV}_{1}$ from baseline were observed in the FFC $(p=0.004,0.003), \mathrm{FBC}(p=0.014,0.011)$, and VFC $(p=0.032,0.023)$ groups at $30 \mathrm{~min}$. Improvements in respiratory resistance at $5-20 \mathrm{~Hz}$ from baseline at $60 \mathrm{~min}$, resonant frequency, respiratory system reactance at $5 \mathrm{~Hz}$, and low-frequency reactance area from baseline were observed at $1 \mathrm{~min}$ in the FFC group ( $p=0.014,0.002,0.027,0.018$, respectively).

Conclusion: FFC administered using a pMDI showed favorable delivery to peripheral airways and significantly more rapid action promptly after inhalation as compared with other ICS/ 
LABA preparations inhaled using a DPI, thus broadening the potential therapeutic options for asthma.

Trial Registration Number: UMIN000029379. Funding: Kyorin Pharmaceutical Co., Ltd.

Keywords: Asthma; ICS/LABA combination therapy; Respiratory function; Respiratory resistance; Forced oscillation technique (FOT)

\section{INTRODUCTION}

Bronchial asthma is a respiratory disease characterized by chronic airway inflammation, mainly involving eosinophils, and resultant reversible airflow obstruction. Management and treatment of asthma thus aim primarily to avoid or eliminate exacerbating factors that trigger airway inflammation and airflow obstruction, and also include pharmacotherapy to reduce inflammation, dilate airways, and ameliorate airway hypersensitivity and obstruction. The Japanese guidelines for asthma prevention and management (JGL2015) [1] and various oversea guidelines for asthma treatment recommend first-line therapy with an inhaled corticosteroid (ICS), which has an anti-inflammatory effect. If ICS monotherapy fails to provide adequate control, the concurrent use of a long-acting $\beta_{2}$ agonist (LABA) or another long-term controller that mainly has a bronchodilatory effect is recommended. Reflecting these recommendations, ICS/LABA combination products are commonly used in current clinical practice. Asthmatic inflammation is not limited to central airways, and is well known to extensively involve peripheral airways and alveoli [2]. Compared with central airways, peripheral airways represent a "silent zone" with minimal manifestations, although small airways with a luminal diameter of less than $2 \mathrm{~mm}$ account for over $90 \%$ of all airways based on the total volume or total cross-sectional area. This means that patients receiving ICS/LABA combination therapy in clinical practice may still suffer peripheral airway inflammation [3]. This problem can be addressed by using an inhaled medication that can be delivered to peripheral airways and rapidly acts to reduce airflow obstruction, thereby improving the airway environment and in turn the potency of ICS therapy. Clinicians select ICS/LABA combination preparations based on guidelines, and tend to prefer products with (1) good anti-inflammatory effects that enable prolonged effective control of chronic airway inflammation, including that of peripheral airways, (2) a simple inhaler (device) that is easy to use, and (3) a less frequent dosing schedule for patient convenience. On the other hand, in a recent Internet-based patient questionnaire survey, $81 \%$ of asthma patients reported that rapid onset of action was the most desirable characteristic of inhaled asthma medications [4]. Thus, currently, the most desirable inhaled medication would appear to be one that fulfills the two conditions of rapid onset of action (enabling prompt symptomatic relief) and effective control of airway inflammation, including that of peripheral airways.

Currently in Japan, three ICS/LABA combination products are used in clinical practice: a formoterol/budesonide combination (FBC) that is delivered by a dry-powder inhaler (DPI) and was released in 2009, a vilanterol/fluticasone combination (VFC) that is delivered as a DPI and was released in 2013, and a formoterol/ fluticasone combination (FFC) that is delivered as an aerosol and was released in 2013. All of these products are expected to exert both a potent anti-asthmatic anti-inflammatory effect and rapid action. Specifically, FBC has been approved for single maintenance and reliever therapy (SMART), as it contains formoterol, a LABA that is expected to exert rapid action [5]. VFC contains vilanterol, a LABA that is also expected to exert rapid action [6]. As with FBC, FFC contains formoterol, which is expected to exert rapid action [7]. In addition, FFC is inhaled using a pressurized metered-dose inhaler (pMDI) device, not a DPI, and the use of a pMDI is associated with improved effects on peripheral airways. Our hypothesis was that these ICS/LABA combination products may provide different clinical benefits because they consist of different ICSs and LABAs that have different characteristics and are delivered by different inhalers. However, studies that directly compare different ICS/LABA products in terms of their rapid effects on respiratory 
$\mathbf{a}$

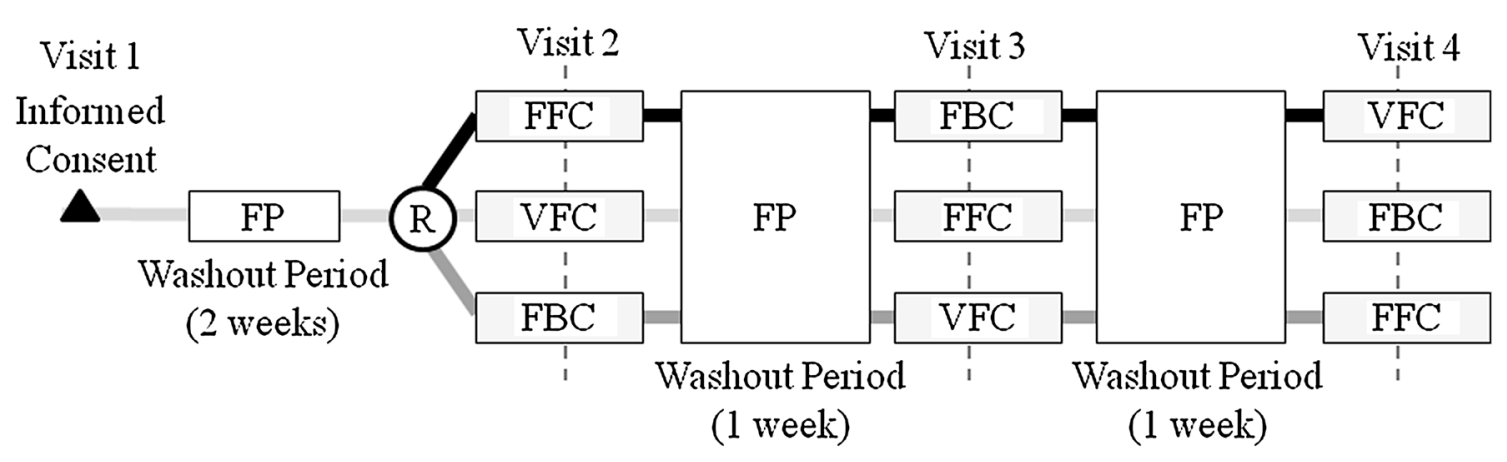

b

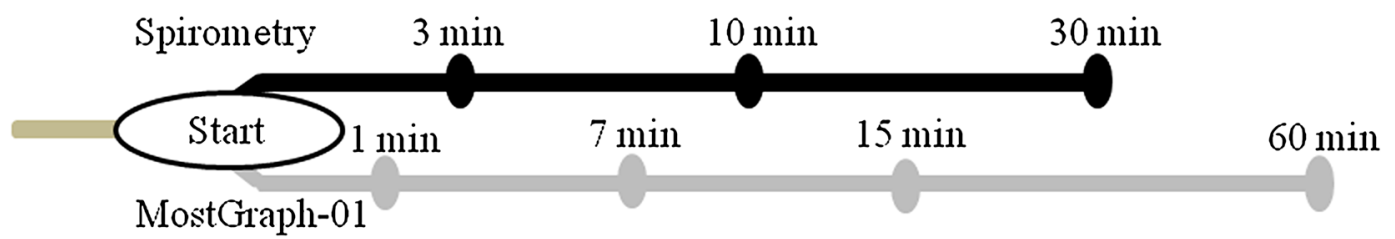

Fig. 1 a Study design for evaluating the rapidity of action of ICS/LABA combination products on pulmonary function. Patients were asked not to inhale ICS on the

function are limited. The present study was thus conducted to compare the rapid effects on the central and peripheral airways of three different ICS/LABA combination products after singledose inhalation.

\section{METHODS}

\section{Study Design}

This was an open-label, randomized, three-period, three-armed crossover study in asthma patients who visited Tohno Chuo Clinic (Mizunami City, Gifu, Japan) between October 2017 and December 2017.

In this three-period study, the medications inhaled at visits 2,3 , and 4 were FFC, FBC, and VFC, respectively; VFC, FFC, and FBC, respectively; and $\mathrm{FBC}, \mathrm{VFC}$, and $\mathrm{FFC}$, respectively (Fig. 1a).

This study was approved by the ethics review committee of Shinagawa East One Medical Clinic, Medical Corporation IHL, and day of a visit. b Time points for performing pulmonary function tests at visits 2,3 , and 4 . ICS inhaled corticosteroid, $L A B A$ long-acting $\beta_{2}$ agonist

conducted in compliance with the Declaration of Helsinki (revised in October 2013) and the Ethical Guidelines for Medical and Health Research Involving Human Subjects. Prior to the study, written informed consent was obtained from all subjects after they had been provided with sufficient explanation and had attained an understanding of the study. The study protocol was registered with the University Hospital Medical Information Network (UMIN) Clinical Trials Registry (UMIN000029379) prior to the initiation of the study. This study was audited by I'ROM Co., Ltd. (Tokyo, Japan).

\section{Participants}

Subjects were outpatients with mild to moderate persistent asthma who were aged 20 years or older but younger than 80 years and were receiving step 2 or 3 asthma treatment with a control level of "well controlled" or "not well controlled (controlled to mild intermittent 
asthma)" [1]. They also had an Asthma Control Questionnaire (ACQ) score of 0.75 or less, and had not suffered any exacerbation during the 3 months prior to the study. Patients were excluded if they had chronic obstructive pulmonary disease (COPD), asthma-COPD overlap syndrome (ACOS), a smoking history of 10 pack-years or more, chronic respiratory tract infection, serious hepatic, renal, or cardiac disease, malignancy, pregnancy or possible pregnancy; had used ICS/LABA during a washout period; had undergone a change in fluticasone propionate (FP) Diskus ${ }^{\circledR}$ dosage; or were otherwise inappropriate for the study in the opinion of the principal investigator.

\section{Intervention}

Subjects were randomly assigned to either the FFC group, the VFC group, or the FBC group in a 1:1:1 ratio using a permuted block method. The subjects allocated to FFC at visit 2 were then allocated to FBC at visit 3 and then VFC at visit 4. During the washout periods, FP Diskus ${ }^{\circledR}$ was used (Fig. 1a). Under the supervision of a specified staff member, subjects inhaled the appropriate inhalant (i.e., FFC, VFC, or FBC). Subsequently, spirometry was performed at 3, 10, and $30 \mathrm{~min}$ after inhalation. Forced oscillation technique (FOT) measurements using MostGraph-01 (Chest M.I. Inc., Tokyo, Japan) were performed at $1,7,15$, and $60 \mathrm{~min}$ after inhalation (Fig. 1b). On the day of a visit, each subject avoided using FP Diskus ${ }^{\circledR}$.

The dose of FFC, VFC, or FBC used in this study (Table $\mathrm{S} 1$ in the Electronic supplementary material, ESM) was in accordance with the approved clinical dose for each product, i.e., one puff as the daily dose for VFC or two puffs as half the daily dose for FFC or FBC.

\section{Primary and Secondary Outcome Measures}

Forced vital capacity (FVC), forced expiratory volume in $1 \mathrm{~s}\left(\mathrm{FEV}_{1}\right), \%$ of predicted normal forced expiratory volume in $1 \mathrm{~s}\left(\% \mathrm{FEV}_{1}\right)$, and inspiratory capacity (IC) were measured using spirometry. In addition, the respiratory resistances at $5 \mathrm{~Hz}(\mathrm{R} 5)$ and $20 \mathrm{~Hz}(\mathrm{R} 20), \mathrm{R} 5$ $\mathrm{R} 20$, as well as the resonant frequency (Fres), the respiratory system reactance at $5 \mathrm{~Hz}$ (X5), and the low-frequency reactance area (ALX) were measured using FOT.

$\mathrm{FEV}_{1}$ was selected as the primary endpoint since it is an important and reliable parameter of central airway function. The onset of action of the medication on central airway function was evaluated in this study. The onset of action on the peripheral airway was a secondary endpoint. The primary endpoint in this study was the change in $\mathrm{FEV}_{1}$ from baseline at $3 \mathrm{~min}$ $\left(\triangle \mathrm{FEV}_{1}\right.$ at $\left.3 \mathrm{~min}\right)$ after inhalation, which was compared across the groups. The secondary endpoint was $\mathrm{FEV}_{1}$ at $30 \mathrm{~min}\left(\triangle \mathrm{FEV}_{1}\right.$ at $\left.30 \mathrm{~min}\right)$, compared across the groups. In addition, \%FEV 1 , FVC, IC, R5, R20, R5-20, X5, Fres, and ALX relative to the baseline were compared within and across the groups (Fig. 1b). The asthma control status was assessed using the ACQ (Asthma Control Questionnaire) at each visit and the JACS (Japan Asthma Control Survey) [8] at visit 2 .

Adverse events during the study period were also assessed.

\section{Statistical Analyses}

The sample size was determined with reference to a study reported by Kempsford et al. [6], in which asthma patients on inhaled fluticasone propionate $200-500 \mu \mathrm{g}$ or an equivalent corticosteroid therapy received add-on vilanterol (25-100 $\mu \mathrm{g}$ ) during the study period, leading to improved respiratory function at $5 \mathrm{~min}$. In the present study, assuming a change of $440 \mathrm{~mL}$ in $\mathrm{FEV}_{1}$ from baseline after inhalation, and that the corresponding value after the inhalation of VFC was $200 \mathrm{~mL}$, with a standard deviation (SD) of $50 \%$, the number of patients needed to detect significant differences between the preparations at a significance level of 0.05 and with a power of 0.9 was 27 . To allow for a $40 \%$ dropout rate, the sample size was set to 45 (the enrollment at visit 2 was 15 patients).

Data were expressed as the mean \pm standard error. The significance level was set at 5\%. When analyzing data with a normal 
distribution, Student's $t$ test was used for intergroup comparisons and the paired $t$ test for intragroup comparisons of data obtained at different times. For data with a non-normal distribution, the Wilcoxon rank sum test was used for intergroup comparisons and the Wilcoxon signed-rank sum test was employed for intragroup comparisons of data obtained at different times. All statistical analyses were performed using the JMP software (ver. 10, SAS Institute, Cary, NC, USA).

\section{RESULTS}

\section{Study Participants}

Fifteen outpatients with bronchial asthma were enrolled in the study. Patient characteristics are shown in Table 1 . The asthma control levels of all the patients met the step 3 (moderate asthma) criteria of JGL2015. The ACQ and JACS scores and the value of fractional exhaled nitric oxide (FeNO) also show that the asthma was very well controlled in the patients. The enrolled patients were all female (mean age $63.3 \pm 9.5$ years). The mean duration of asthma was $27.2 \pm 19.8$ months. The ACQ scores were $0.13,0.14$, and 0.12 at visit 2 , visit 3 , and visit 4 , respectively, which suggests that the patients maintained stable, well-controlled asthma levels over the study period. Also, the JACS score was 8.7 at visit 2 .

\section{Primary and Secondary Outcome Measures}

\section{Respiratory Function by Spirometry}

The primary endpoint ( $\Delta \mathrm{FEV}_{1}$ at $\left.3 \mathrm{~min}\right)$ did not significantly differ among the three groups (Fig. 2a). In addition, neither $\Delta \% \mathrm{FEV}_{1}$ at $3 \mathrm{~min}$, $\Delta \mathrm{FEV}_{1}$ at $30 \mathrm{~min}$, nor $\Delta \% \mathrm{FEV}_{1}$ at $30 \mathrm{~min}$ showed any significant difference among the three groups (Fig. 2b-d). As for intragroup comparisons, the change in $\mathrm{FEV}_{1}$ from baseline in the FFC group was not significant at $3 \mathrm{~min}$ $(p=0.065)$, but significant improvements were seen at $10 \mathrm{~min} \quad(p=0.021)$ and $30 \mathrm{~min}$ $(p=0.004)$. In the FBC group, the change in
Table 1 Patient characteristics

\begin{tabular}{|c|c|}
\hline Age (years) & $63.3 \pm 9.5$ \\
\hline Male/female $(n)$ & $0 / 15$ \\
\hline $\begin{array}{l}\text { Severity (mild persistent/moderate } \\
\text { persistent) }(n)\end{array}$ & $0 / 15$ \\
\hline Treatment step $2 / 3(n)$ & $0 / 15$ \\
\hline $\begin{array}{l}\text { Symptoms in current treatment (controlled/ } \\
\text { mild intermittent) }(n)\end{array}$ & $15 / 0$ \\
\hline Disease type (atopic/nonatopic) $(n)$ & $3 / 12$ \\
\hline Asthma duration (months) & $27.2 \pm 19.8$ \\
\hline Smoking status $(n)$ & $13 / 2 / 0^{\mathrm{a}}$ \\
\hline Years of smoking & $1.8 \pm 5.3$ \\
\hline FeNO (ppb) & $16.7 \pm 6.8$ \\
\hline Comorbidity (yes/no) $(n)$ & $9 / 6$ \\
\hline ACQ (score) & $0.13 \pm 0.19$ \\
\hline JACS (score) & $8.7 \pm 0.4$ \\
\hline \multicolumn{2}{|l|}{ Spirometry } \\
\hline $\mathrm{FEV}_{1}(\mathrm{~L})$ & $1.85 \pm 0.42$ \\
\hline $\mathrm{FEV}_{1} \%(\%)$ & $77.74 \pm 5.89$ \\
\hline$\% \mathrm{FEV}_{1}(\%)$ & $95.83 \pm 18.09$ \\
\hline $\mathrm{IC}(\mathrm{L})$ & $1.76 \pm 0.36$ \\
\hline FVC (L) & $2.39 \pm 0.54$ \\
\hline \multicolumn{2}{|c|}{ FOT measurements obtained using MostGraph-01 } \\
\hline $\mathrm{R} 5$ index $\left(\mathrm{cmH}_{2} \mathrm{O} / \mathrm{L} / \mathrm{s}\right)$ & $3.58 \pm 1.22$ \\
\hline $\mathrm{R} 20$ index $\left(\mathrm{cmH}_{2} \mathrm{O} / \mathrm{L} / \mathrm{s}\right)$ & $3.17 \pm 0.84$ \\
\hline $\mathrm{R} 5-\mathrm{R} 20$ index $\left(\mathrm{cmH}_{2} \mathrm{O} / \mathrm{L} / \mathrm{s}\right)$ & $0.40 \pm 0.48$ \\
\hline $\mathrm{X} 5$ index $\left(\mathrm{cmH}_{2} \mathrm{O} / \mathrm{L} / \mathrm{s}\right)$ & $-0.89 \pm 0.95$ \\
\hline Fres index $(\mathrm{Hz})$ & $9.84 \pm 4.30$ \\
\hline ALX index $\left(\mathrm{cmH}_{2} \mathrm{O} / \mathrm{L} / \mathrm{s} \mathrm{Hz}\right)$ & $5.03 \pm 7.65$ \\
\hline
\end{tabular}

Values are the mean $\pm \mathrm{SD}$, unless otherwise indicated $A C Q$ Asthma Control Questionnaire, $A L X$ low-frequency reactance area, $F E V_{1}$ forced expiratory volume in $1 \mathrm{~s}, F E V_{1} \%$ forced expiratory volume $\%$ in $1 \mathrm{~s}, \% F E V_{1} \%$ of predicted normal forced expiratory volume in $1 \mathrm{~s}$, Fres resonant frequency, $F V C$ forced vital capacity, $I C$ inspiratory capacity, $J A C S$ Japan Asthma Control Survey, $R 5$ respiratory resistance at $5 \mathrm{~Hz}, R 20$ respiratory resistance at $20 \mathrm{~Hz}, X 5$ respiratory system reactance at $5 \mathrm{~Hz}$, Fres resonant frequency, $A L X$ lowfrequency reactance area

${ }^{a}$ Never smoked/former smoker/current smoker

$\mathrm{FEV}_{1}$ from baseline was not significant at $3 \mathrm{~min}$ $(p=0.132)$, but significant improvements were observed at $10 \mathrm{~min}(p=0.014)$ and $30 \mathrm{~min}$ 

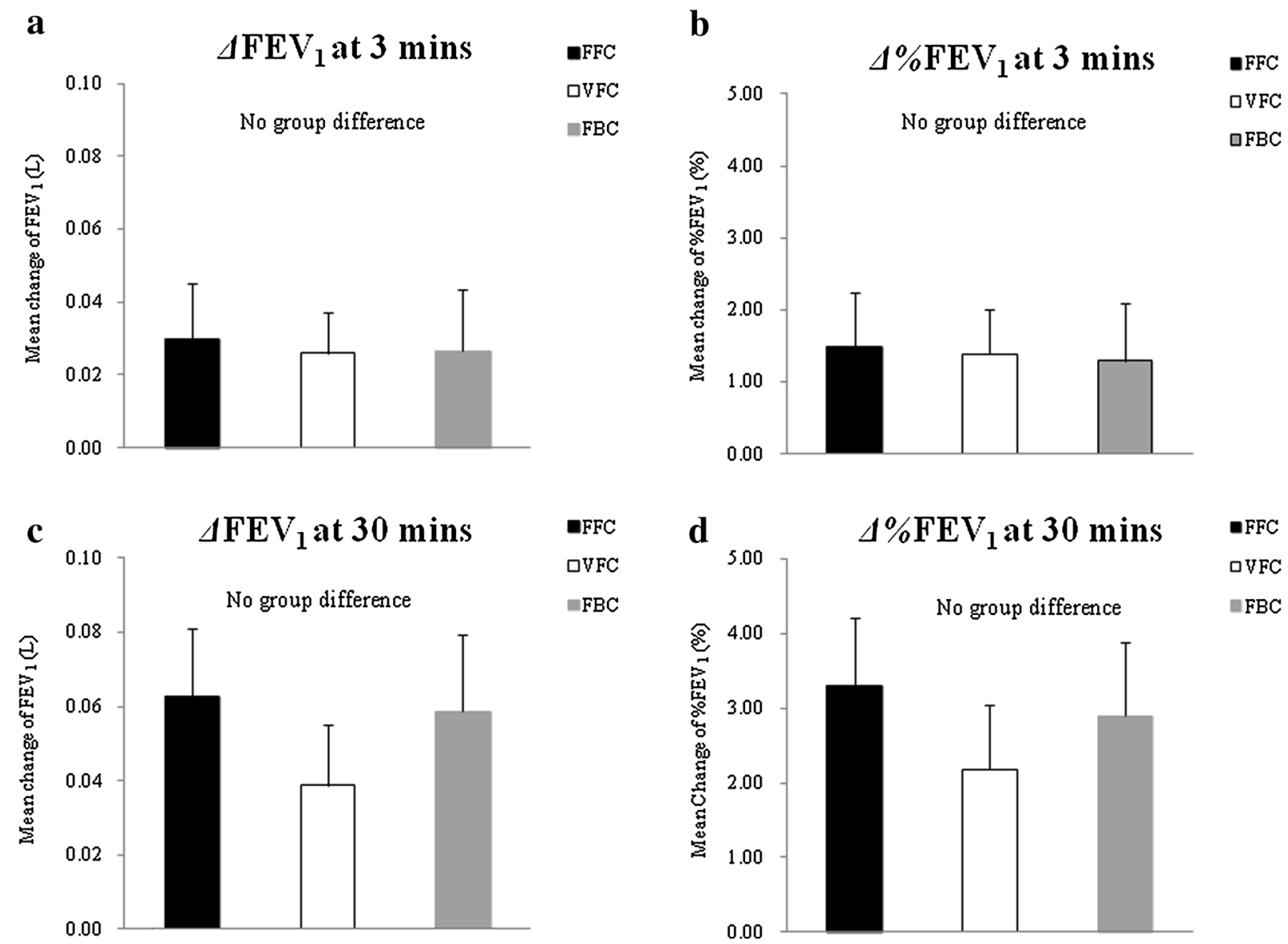

Fig. 2 a-d Mean changes in post-dose $F E V_{1}$ from baseline at a $3 \mathrm{~min}$ and c $30 \mathrm{~min}$, and mean changes in post-dose \% $\mathrm{FEV}_{1}$ from baseline at $\mathbf{b} 3 \mathrm{~min}$ and d $30 \mathrm{~min}$. Student's

$(p=0.014)$. In the VFC group, however, the change in $\mathrm{FEV}_{1}$ from baseline was significant at $3 \mathrm{~min} \quad(p=0.035)$ and $30 \mathrm{~min} \quad(p=0.032)$ (Fig. 3a). As for the intragroup comparisons of $\% \mathrm{FEV}_{1}$, the change from baseline in the FFC group was not significant at $3 \mathrm{~min}(p=0.069)$, but significant improvements were seen at $10 \mathrm{~min}(p=0.016)$ and $30 \mathrm{~min}(p=0.003)$. Also in the FBC group, significant improvements were noted at $10 \mathrm{~min}(p=0.006)$ and $30 \mathrm{~min}$ $(p=0.011)$. In the VFC group, however, significant improvements were observed at $3 \mathrm{~min}$ $(p=0.040)$ and $30 \mathrm{~min}(p=0.023)$, but there was no significant difference at $10 \mathrm{~min}$ (Fig. 3b).

As for intragroup comparisons of $\mathrm{FVC}$, the change from baseline at 10 min was significant

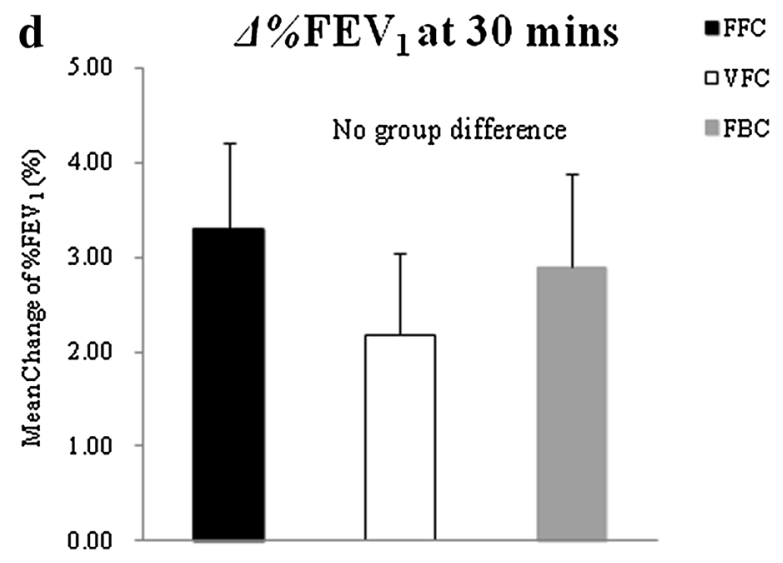

$t$ test was used for intergroup comparisons. $F E V_{1}$ forced expiratory volume in $1 \mathrm{~s}$

for the FFC group $(p=0.049)$ but not for the FBC group or the VFC group (Fig. 3c). In the intergroup and intragroup comparisons of IC, neither the FFC, the VFC, nor the FBC group showed any significant differences (Fig. 3d).

\section{Respiratory Resistance by FOT}

The results are shown in Table 2 . For both R5 and R20, intragroup comparisons showed significantly decreased resistance from baseline at $60 \mathrm{~min}$ in all three groups (FFC, FBC, and VFC). As for R5-R20, the FFC group showed significant improvement from baseline at $60 \mathrm{~min}$ $(p=0.014)$. For $\mathrm{X} 5$, intragroup comparisons for the FFC group showed a significant improvement from baseline at $1 \mathrm{~min}(p=0.027)$, which 

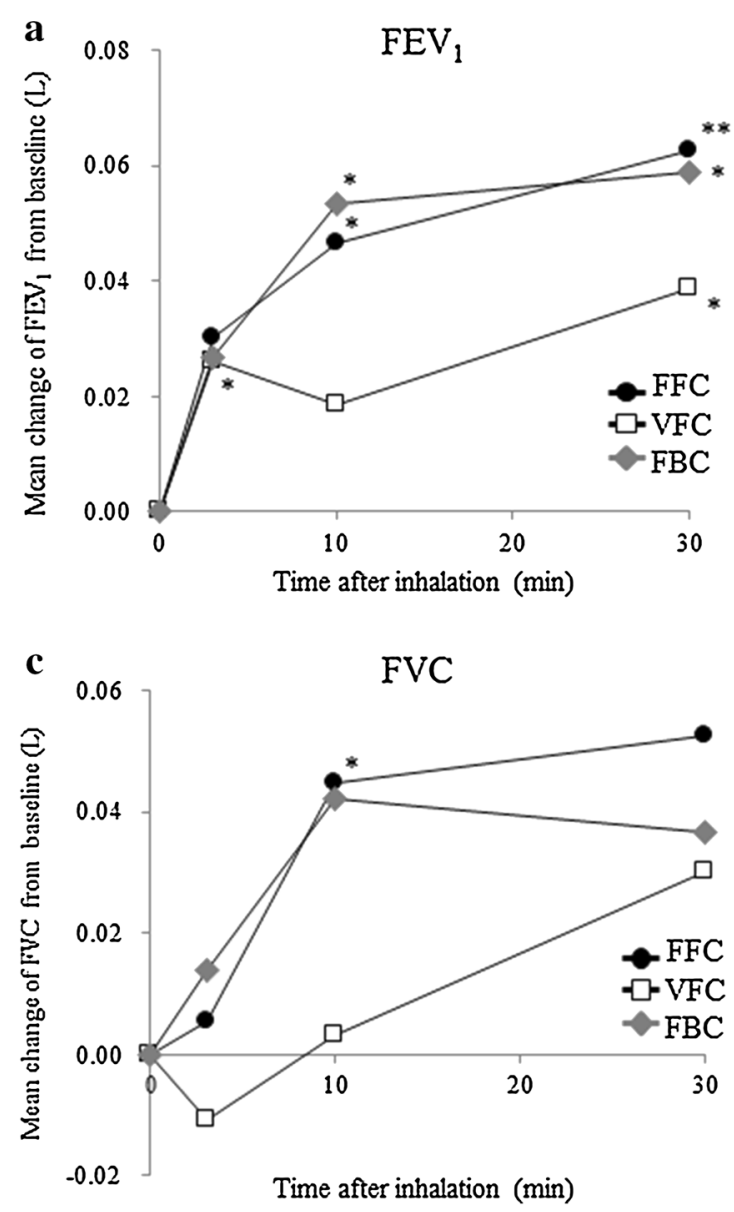

Fig. 3 a-d Mean changes in respiratory function test indices $\left(\mathbf{a} \mathrm{FEV}_{1}, \mathbf{b} \% \mathrm{FEV}_{1}\right.$, c FVC, d IC) from baseline over a period of $30 \mathrm{~min}$ following inhalation. The paired $t$ test was used for intragroup comparisons of outcomes at different time points. Statistical significance: ${ }^{*} p<0.05$, ${ }^{* *} p<0.01$ compared with baseline. $F E V_{1}$ forced expiratory

was maintained until $60 \mathrm{~min}$. In the VFC group, X5 was significantly improved from $7 \mathrm{~min}$ $(p=0.029)$ on. In the FBC group, X5 did not significantly change. For Fres, intragroup comparisons for the FFC group showed a significant improvement from baseline at $1 \mathrm{~min}$ $(p=0.002)$, which was maintained until $60 \mathrm{~min}$. In the VFC group, Fres was significantly improved from 7 min on. In the FBC group, Fres did not show a significant change at any time point.

For ALX, intragroup comparisons for the FFC group showed a significant improvement from
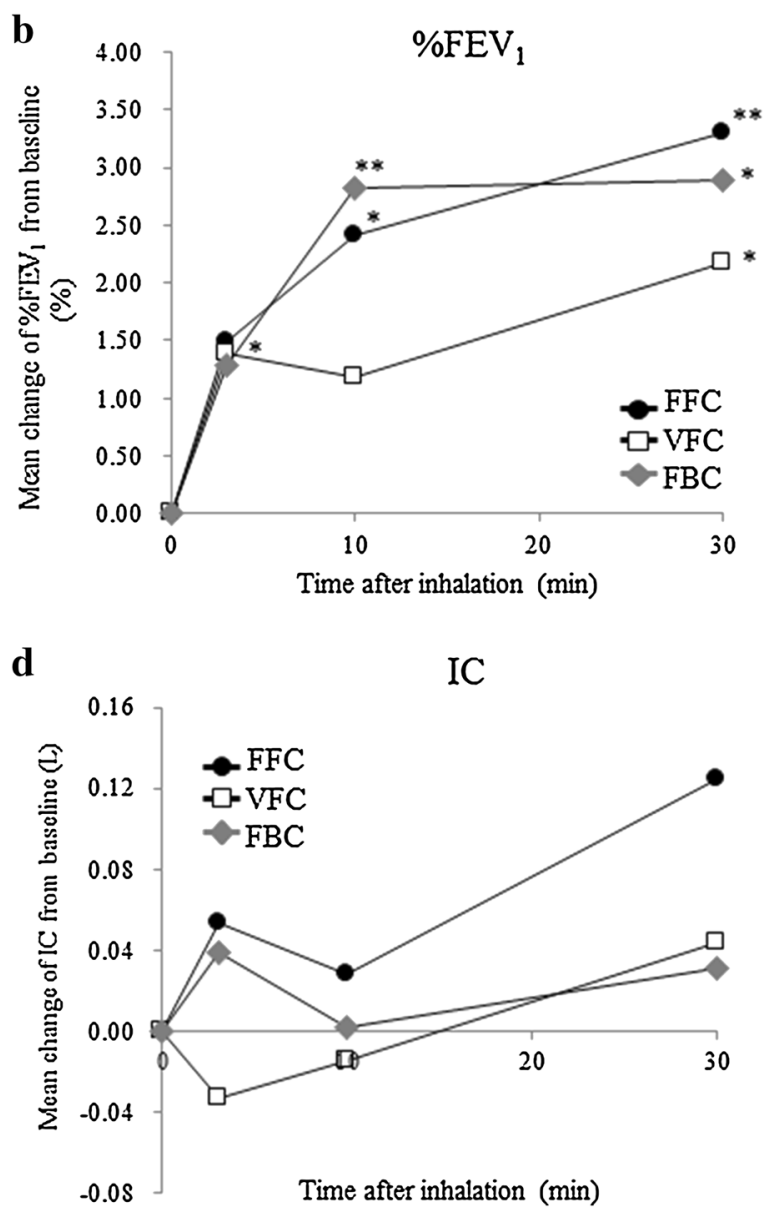

volume in $1 \mathrm{~s}, \% \mathrm{FEV}_{1} \%$ of predicted normal forced expiratory volume $\%$ in $1 \mathrm{~s}$, FVC forced vital capacity, $I C$ inspiratory capacity

baseline at $1 \mathrm{~min}(p=0.018)$, which was maintained until $60 \mathrm{~min}$. In the VFC group, ALX was significantly improved at $15 \mathrm{~min}(p=0.010)$. In the FBC group, ALX did not show any significant change at any time point. Data on each index of expiratory-inspiratory respiratory resistance are shown in Table S2 of the ESM.

\section{Adverse Events}

No adverse events were observed during the study period in any of the treatment groups. 
Table 2 Comparison of the mean \pm SEM (measured by MostGraph-01) values

\begin{tabular}{|c|c|c|c|c|c|}
\hline & Pre-dose & $1 \mathrm{~min}$ & $7 \mathrm{~min}$ & $15 \mathrm{~min}$ & $60 \mathrm{~min}$ \\
\hline \multicolumn{6}{|c|}{$\mathrm{R} 5\left(\mathrm{cmH}_{2} \mathrm{O} / \mathrm{L} / \mathrm{s}\right)$} \\
\hline FFC & $3.55 \pm 0.30$ & $3.48 \pm 0.28$ & $3.23 \pm 0.21$ & $3.26 \pm 0.26$ & $2.99 \pm 0.24^{* *}$ \\
\hline VFC & $3.65 \pm 0.32$ & $3.80 \pm 0.32$ & $3.64 \pm 0.29$ & $3.43 \pm 0.28$ & $3.11 \pm 0.23^{* *}$ \\
\hline $\mathrm{FBC}$ & $3.57 \pm 0.34$ & $3.58 \pm 0.27$ & $3.45 \pm 0.29$ & $3.39 \pm 0.28$ & $3.15 \pm 0.25^{*}$ \\
\hline \multicolumn{6}{|c|}{$\mathrm{R} 20\left(\mathrm{cmH}_{2} \mathrm{O} / \mathrm{L} / \mathrm{s}\right)$} \\
\hline FFC & $3.18 \pm 0.21$ & $3.16 \pm 0.20$ & $2.97 \pm 0.15^{*}$ & $2.96 \pm 0.17$ & $2.77 \pm 0.18^{* *}$ \\
\hline VFC & $3.20 \pm 0.22$ & $3.33 \pm 0.21$ & $3.16 \pm 0.20$ & $3.07 \pm 0.18$ & $2.82 \pm 0.15^{* *}$ \\
\hline $\mathrm{FBC}$ & $3.18 \pm 0.23$ & $3.21 \pm 0.17$ & $3.10 \pm 0.20$ & $3.09 \pm 0.19$ & $2.87 \pm 0.17^{* *}$ \\
\hline \multicolumn{6}{|c|}{$\mathrm{R} 5-\mathrm{R} 20\left(\mathrm{cmH}_{2} \mathrm{O} / \mathrm{L} / \mathrm{s}\right)$} \\
\hline FFC & $0.37 \pm 0.11$ & $0.32 \pm 0.11$ & $0.26 \pm 0.11$ & $0.30 \pm 0.11$ & $0.22 \pm 0.10^{*}$ \\
\hline VFC & $0.45 \pm 0.13$ & $0.47 \pm 0.13$ & $0.47 \pm 0.13$ & $0.36 \pm 0.13$ & $0.29 \pm 0.13$ \\
\hline $\mathrm{FBC}$ & $0.39 \pm 0.14$ & $0.37 \pm 0.14$ & $0.35 \pm 0.13$ & $0.30 \pm 0.14$ & $0.28 \pm 0.12$ \\
\hline \multicolumn{6}{|c|}{$\mathrm{X} 5\left(\mathrm{cmH}_{2} \mathrm{O} / \mathrm{L} / \mathrm{s}\right)$} \\
\hline FFC & $-0.90 \pm 0.26$ & $-0.76 \pm 0.24^{*}$ & $-0.64 \pm 0.21^{* *}$ & $-0.59 \pm 0.14^{* *}$ & $-0.63 \pm 0.19^{* *}$ \\
\hline VFC & $-1.02 \pm 0.28$ & $-0.94 \pm 0.30$ & $-0.73 \pm 0.22^{*}$ & $-0.76 \pm 0.26^{* *}$ & $-0.74 \pm 0.23^{* * a}$ \\
\hline $\mathrm{FBC}$ & $-0.75 \pm 0.19$ & $-0.77 \pm 0.24$ & $-0.67 \pm 0.18$ & $-0.72 \pm 0.24$ & $-0.72 \pm 0.22$ \\
\hline \multicolumn{6}{|c|}{ Fres $(\mathrm{Hz})$} \\
\hline FFC & $9.75 \pm 1.16$ & $8.86 \pm 0.97^{* *}$ & $8.29 \pm 0.91^{* * a}$ & $8.36 \pm 0.82^{* *}$ & $8.28 \pm 0.87^{* *}$ \\
\hline VFC & $10.51 \pm 1.22$ & $9.70 \pm 1.21$ & $8.65 \pm 1.02^{*}$ & $8.55 \pm 1.02^{* *}$ & $8.58 \pm 0.97^{* *}$ \\
\hline $\mathrm{FBC}$ & $9.25 \pm 1.00$ & $8.84 \pm 0.97$ & $8.51 \pm 0.86$ & $8.40 \pm 0.92$ & $8.56 \pm 0.94$ \\
\hline \multicolumn{6}{|c|}{$\operatorname{ALX}\left(\mathrm{cmH}_{2} \mathrm{O} / \mathrm{L} / \mathrm{s} \mathrm{Hz}\right)$} \\
\hline FFC & $5.21 \pm 2.17$ & $4.11 \pm 1.92 *$ & $3.30 \pm 1.46^{* *}$ & $2.76 \pm 0.85^{* *}$ & $3.16 \pm 1.27^{* *}$ \\
\hline VFC & $6.00 \pm 2.31$ & $5.62 \pm 2.52$ & $4.06 \pm 1.69$ & $4.17 \pm 1.98^{* *}$ & $3.92 \pm 1.82^{* * a}$ \\
\hline $\mathrm{FBC}$ & $3.88 \pm 1.43$ & $4.16 \pm 1.82$ & $3.32 \pm 1.19$ & $3.78 \pm 1.73$ & $3.74 \pm 1.65$ \\
\hline
\end{tabular}

Data are expressed as the mean \pm SEM

$A L X$ low-frequency reactance area, Fres resonant frequency, $R 5$ respiratory resistance at $5 \mathrm{~Hz}, R 20$ respiratory resistance at $5 \mathrm{~Hz}, X 5$ respiratory system reactance at $5 \mathrm{~Hz}$

${ }^{* *} p<0.01$ vs. baseline value (pre-dose)

${ }^{*} p<0.05$ vs. baseline value (pre-dose)

${ }^{a} p<0.05$, mean change from baseline for FFC or VFC compared with FBC

\section{DISCUSSION}

This crossover study compared FFC, FBC, and VFC in terms of their positive effects on respiratory function, and the rapidity of onset of those effects, as measured by spirometry and FOT. The improvement in $\mathrm{FEV}_{1}$ at $3 \mathrm{~min}$, which was the primary endpoint, did not differ among 
the three groups (Fig. 2a), and there was no intergroup difference at $30 \mathrm{~min}$ either (Fig. 2c). As for intragroup comparisons, the changes in $\mathrm{FEV}_{1}$ from baseline indicated significant improvements at 10 and $30 \mathrm{~min}$ in the FFC group ( $p=0.021$ and $p=0.004$, respectively) and the FBC group $(p=0.014$ and $p=0.014$, respectively) (Fig. 3a). In the VFC group, however, $\mathrm{FEV}_{1}$ was significantly improved from baseline at $3 \mathrm{~min}(p=0.035)$ and $30 \mathrm{~min}$ $(p=0.032)$. Similar trends were observed for $\% \mathrm{FEV}_{1}$. In addition, only the FFC group showed a significant improvement in FVC at $10 \mathrm{~min}$ (Fig. 3c). Significant improvements were observed in these respiratory function test parameters, which reflect the condition of relatively large airways. FFC, a pMDI preparation of inhaled ICS/LABA, appears to exert a greater bronchodilatory effect than DPI preparations of inhaled ICS/LABA. As shown in Fig. 3d, the FFC group showed a tendency for improvement in IC at $30 \mathrm{~min}$, although this improvement did not reach statistical significance when comparisons were made with the VFC $(p=0.14)$ and FBC $(p=0.09)$ groups, respectively. The parameter IC generally reflects the degree of air trapping in the lungs of asthma patients. However, air trapping did not occur in the wellcontrolled, asymptomatic patients recruited in this study. The tendency for IC to improve in the FFC group may be attributable to the alleviated residual air trapping as a result of the rapid onset of the effect on peripheral airways in the FFC group. These results are consistent with the FOT results. As shown in Table 2, in the FFC group, the parameters X5, ALX, and Fres, which reflect the condition of peripheral airways, showed significant improvements from $1 \mathrm{~min}$ onwards, which were maintained even at $60 \mathrm{~min}$. In the VFC group, those parameters showed significant improvements slightly later than in the FFC group-at $7 \mathrm{~min}$, and those improvements were maintained until $60 \mathrm{~min}$. In the FBC group, those parameters did not significantly improve during the 60 -min period. We hypothesize that FFC, which contains formoterol, acts rapidly, and it may have a better effect on peripheral airways when delivered with the pMDI device. The results of the present study support our hypothesis.
This study was the first to measure the effects of inhaled ICS/LABA combinations on pulmonary function, including central and peripheral airways, immediately after singledose inhalation.

The results for the VFC group, which showed that $\mathrm{FEV}_{1}$ and $\% \mathrm{FEV}_{1}$ significantly improved from baseline at $3 \mathrm{~min}$ but then dropped at $10 \mathrm{~min}$, should be kept in mind when selecting prescription combination products that are inhaled once daily for patients with asthma. With once-daily VFC therapy, a transient bronchodilatory effect at $3 \mathrm{~min}$ was followed by no significant improvement. Furthermore, notably, the dose employed in the FFC and FBC groups was two puffs, which was half the usual daily dose, while the dose applied in the VFC group was one puff of $200 \mu \mathrm{g}$, which was the usual daily dose. Based on the potency of the steroid, the dose taken in one puff by the VFC group was at least twofold that of the dose taken in one puff by the FFC and FBC groups, and this should be carefully considered when interpreting the results of this study. Once-daily medication thus warrants caution when used in symptomatic patients, patients at a high risk of exacerbation, elderly patients, and so on, and requires appropriate selection of the patients to be treated. However, once-daily inhalation using a simple, easy-to-use device is convenient for patients. VFC, once-daily inhalation was favorable combination inhalant for patient hard to deal with twice-daily. On the other hand, FFC and FBC, which are designed for twice-daily dosing, provided rapid beneficial effects twice daily on the respiratory function parameters $\mathrm{FEV}_{1}, \% \mathrm{FEV}_{1}$, and FVC.

While FBC has been approved for SMART, as it contains formoterol (a LABA that is expected to exert rapid action [5]), the study results showed a difference in the rapidity of the bronchodilatory effect between FFC and FBC, despite both containing the same LABA component (formoterol). Although drug particle size is related to the efficiency of drug delivery to peripheral airways, and smaller particles are more likely to be delivered to smaller airways, the rapid improvement in peripheral airways observed in this study cannot be explained by the difference in particle size because the 
particle diameter of FFC is 3.1-3.6 $\mu \mathrm{m}$-rather larger than that of $\mathrm{FBC}$, which has a mean particle diameter of 2.2-2.4 $\mu \mathrm{m}$. Among other factors related to the drug delivery to peripheral airways, the difference in inhalation pattern may play a major role. For FBC, which is designed to be inhaled using a DPI, patients should inhale the medication through their own efforts, and are thus required to use a "quick and forceful" inhalation pattern. For FFC, which is designed to be inhaled using a pMDI, patients are required to use a "slow and deep" inhalation pattern, synchronizing the inhalation and the pMDI actuation. In patients with remaining peripheral airway inflammation, small peripheral airways with a bronchial diameter of less than $2 \mathrm{~mm}$ are heterogeneously stenosed or obstructed by inflammation [10]. Physically, the medication, inhaled "quickly and forcefully," is first delivered to the bronchi without stenosis or obstruction, while little or no portion of the medication can reach the bronchi stenosed with inflammation. With aerosol medication, on the other hand, the "slow and deep" inhalation pattern is more likely to allow the delivery of part of the medication to peripheral airways with stenosis or an obstruction, which can promptly dilate the peripheral airways. Since the inhalation pattern is repeated for each dosing every day, the aerosol medication is effective in patients with inflammation in peripheral airways. Similarly, a published study compared DPI and pMDI products of salmeterol/fluticasone based on their peripheral-airway-improving effects as measured by FOT, and pMDI was found to significantly improve R5, R5-R20, and X5 [11]. Our data were also consistent with another published study by Iwanaga et al. in which the drug deposition fractions in the peripheral airways were measured using functional respiratory imaging (a novel imaging technology) after the inhalation of FFC, FBC, or VFC; the drug deposition fractions for the ICS component were $27.34,15.31$, and $4.77 \%$, respectively, while those for the LABA component were $26.32,13.89$, or $8.77 \%$, respectively, showing very high drug deposition in peripheral airways with FFC [12].
Limitations of this study include the nonplacebo-controlled comparison of post-market drugs, the fact that this was a single-center study (although the investigators were highly skilled specialists), and the unintentional inclusion of female patients only.

\section{CONCLUSION}

Currently, ICS/LABA combination preparations that improve peripheral airway inflammation and show a rapid onset of action for peripheral airways are desired. In this study, FFC inhaled using a pMDI showed favorable delivery to peripheral airways and more rapid action promptly after inhalation as compared with other ICS/LABA preparations inhaled using a DPI, leading to broader therapeutic options for asthma.

\section{ACKNOWLEDGEMENTS}

We thank the participants in the study.

Funding. This study was financially supported by Kyorin Pharmaceutical Co., Ltd. There was no involvement of the funder in data collection, data management, statistical analyses, the interpretation of the study results, or manuscript preparation. The journal's article processing charges and writing support fee were funded by Kyorin Pharmaceutical Co., Ltd.

Medical Writing and/or Editorial Assistance. WILL Medical Communications assisted the authors in the preparation of the manuscript. All tables/figures are original and were produced by the authors for this particular publication. Study data were collected by the principal investigator. The principal investigator supported the data management, statistical analyses, and the interpretation of the study results.

Authorship. All named authors meet the International Committee of Medical Journal Editors (ICMJE) criteria for authorship of this article, take responsibility for the integrity of 
the work as a whole, and have given their approval for this version to be published. WILL Medical Communications assisted the authors in the preparation of the manuscript. The journal's article processing charges and writing support fee were funded by Kyorin Pharmaceutical Co., Ltd.

Disclosures. Hiroyuki Ohbayashi, Sahori Kudo, and Mitsue Ariga have nothing to disclose.

Compliance with Ethical Guidelines. This study was approved by the ethics review committee of Shinagawa East One Medical Clinic, Medical Corporation IHL, and conducted in compliance with the Declaration of Helsinki (revised in October 2013) and the Ethical Guidelines for Medical and Health Research Involving Human Subjects. Prior to the study, written informed consent was obtained from all of the subjects after they were provided with a sufficient explanation of the study and had attained an understanding of it.

Data Availability. The datasets generated during and/or analyzed during the current study are available from the corresponding author on reasonable request.

Open Access. This article is distributed under the terms of the Creative Commons Attribution-NonCommercial 4.0 International License (http://creativecommons.org/licenses/ by-nc/4.0/), which permits any noncommercial use, distribution, and reproduction in any medium, provided you give appropriate credit to the original author(s) and the source, provide a link to the Creative Commons license, and indicate if changes were made.

\section{REFERENCES}

1. Asthma Prevention and Management Guildeline Preparation Committee. Asthma prevention and management guidelines. Tokyo: Kyowa Kikaku; 2018.
2. Hamid Q, Song Y, Kotsimbos TC, et al. Inflammation of small airways in asthma. J Allergy Clin Immunol. 1997;100:44-51.

3. Ohbayashi $H$, Shibata $N$, Hirose $T$, Adachi $M$. Additional effects of pranlukast in salmeterol/fluticasone combination therapy for the asthmatic distal airway in a randomized crossover study. Pulm Pharmacol Ther. 2009;22:574-9.

4. Ohta K, Minoguchi K. ACTUAL-I: a clinical survey to understand real asthma life for patients-I. Allergy Immunol. 2009;16:1430-40 (in Japanese).

5. Chapman KR, Barnes NC, Greening AP, Jones PW, Pedersen S. Single maintenance and reliever therapy (SMART) of asthma: a critical appraisal. Thorax. 2010;65:747-52.

6. Kempsford R, Norris V, Siederer S. Vilanterol trifenatate, a novel inhaled long-acting $\beta 2$ adrenoceptor agonist, is well tolerated in healthy subjects and demonstrates prolonged bronchodilation in subjects with asthma and COPD. Pulm Pharmacol Ther. 2013;26:256-64.

7. Bodzenta-Lukaszyk A, Dymek A, McAulay K, Mansikka H. Fluticasone/formoterol combination therapy is as effective as fluticasone/salmeterol in the treatment of asthma, but has a more rapid onset of action: an open-label, randomized study. BMC Pulm Med. 2011;11:28.

8. Tohda Y, Hozawa S, Tanaka H. Development of a questionnaire to evaluate asthma control in Japanese asthma patients. Allergol Int. 2018;67:131-7.

9. Heijkenskjöld Rentzhog C, Janson C, Berglund L, et al. Overall and peripheral lung function assessment by spirometry and forced oscillation technique in relation to asthma diagnosis and control. Clin Exp Allergy. 2017;47:1546-54.

10. Busse WW, Banks-Schlegel S, Wenzel SE. Pathophysiology of severe asthma. J Allergy Clin Immunol. 2000;106:1033-42.

11. Hojo M, Shirai T, Hirashima J, Iikura M, Sugiyama $\mathrm{H}$. Comparison of the clinical effects of combined salmeterol/fluticasone delivered by dry powder or pressurized metered dose inhaler. Pulm Pharmacol Ther. 2016;37:43-8.

12. Iwanaga T, Kozuka T, Nakanishi J, et al. Aerosol deposition of inhaled corticosteroids/long-acting $\beta 2$-agonists in the peripheral airways of patients with asthma using functional respiratory imaging, a novel imaging technology. Pulm Ther. 2017;3:219-31. 